\title{
The Priming Effect of Glucose on Insulin Secretion from Isolated Islets of Langerhans
}

\author{
J. P. Ashby and D. Shirling \\ Metabolic Unit, University Department of Medicine, Western General Hospital, Edinburgh, Scotland
}

Summary. Biphasic insulin secretion from perifused rat islets of Langerhans was enhanced if islets had previously been stimulated with glucose $16.6 \mathrm{mmol} / 1$. The priming effect of glucose was reduced if mannoheptulose $(16.6 \mathrm{mmol} / \mathrm{l})$, deuterium oxide $\left(\mathrm{D}_{2} \mathrm{O}\right.$; $98 \% \mathrm{v} / \mathrm{v})$ or adrenaline $(10 \mu \mathrm{mol} / \mathrm{l})$ was included in the medium during the initial stimulation period, or if Calcium was omitted. Glyceraldehyde $(16.6 \mathrm{mmol} / \mathrm{l})$ but not theophylline $(5 \mathrm{mmol} / 1)$ could substitute for glucose during the initial stimulation and make islets more responsive to subsequent stimulation. The results suggest that the priming effect of glucose on insulin secretion may be related to 1) glucose metabolism and 2) $\mathrm{Ca}$ fluxes in the $\mathrm{B}$ cell and the consequent activation of the microtubular system. Neither the generation of intracellular cyclic AMP nor the release of insulin per se appears to be involved in the priming process.

Key words: Biphasic insulin secretion, perifused islets, glucose priming, mannoheptulose, glyceraldehyde, calcium, deuterium oxide, cyclic AMP, adrenaline.

Acute exposure of the rat pancreatic B cell to glucose leads to biphasic secretion which is characterised by a short-lived burst of insulin release (phase 1) followed by a slower progressive rise in the secretory rate known as phase 2 [1-4]. Studies in vivo in man [5] and in vitro with the perfused rat pancreas [6] and perifused islets of Langerhans [7] have shown that a short period of glucose stimulation may also potentiate the secretory response of the $B$ cell to a second pulse of glucose given shortly afterwards. Although it has been suggested that this effect occurs only if the concentration of glucose present during the initial stimulation period is in excess of approximately $14 \mathrm{mmol} / 1$ in man [5] or $11 \mathrm{mmol} / \mathrm{l}$ in perifused rat islets [7], the biochemical mechanisms mediating this phenomenon are poorly understood. In the present study the possible roles of 1) glucose metabolism 2) calcium and the microtubular system, and 3) cyclic AMP have been examined. The experiments were carried out using perifused rat islets of Langerhans.

\section{Materials and Methods}

\section{Isolation and Perifusion of Islets of Langerhans}

Male Wister albino rats weighing approximately $200 \mathrm{~g}$ were fed ad libitum on a standard laboratory diet containing $48 \%$ carbohydrate, $21.3 \%$ protein and $3.4 \%$ fat. Islets were isolated by collagenase digestion [8]. The medium used for extraction and subsequent experiments was a bicarbonate-buffered salt solution with the following ionic composition: $\mathrm{Na}^{+} 141 ; \mathrm{K}^{+} 5.9 ; \mathrm{Ca}^{2+} 2.5$; $\mathrm{Mg}^{2+} 1.2 ; \mathrm{PO}_{4}^{2-} 1.2 ; \mathrm{CT}^{-} 101$ and $\mathrm{HCO}_{3}^{-} 24.9 \mathrm{mmol} / 1 ; \mathrm{pH} 7.4$. The medium was supplemented with the sodium salts of glutamic, lactic and fumaric acids at a concentration of $5 \mathrm{mmol} / \mathrm{l}$ [9]. The gas phase was $\mathrm{O}_{2}: \mathrm{CO}_{2}(95: 5)$. The calcium concentration of "calcium-free' media was $0.03 \mathrm{mmol} / \mathrm{l}$ as determined by atomic absorption spectrophotometry. When islets were exposed to deuterium oxide $\left(\mathrm{D}_{2} \mathrm{O}\right)$ the ionic composition of the medium was unchanged but $\mathrm{D}_{2} \mathrm{O}$ replaced $\mathrm{H}_{2} \mathrm{O}$ to give a final concentration of $98 \%(\mathrm{v} / \mathrm{v})$. The $\mathrm{pH}$ was adjusted to that of the control medium. The basal concentration of glucose present during islet isolation and perifusion was $2.7 \mathrm{mmol} / \mathrm{l}$.

Thirty islets were loaded into each channel of a multi-channel perifusion system [7] and equilibrated by perifusion with medium containing basal glucose for $40 \mathrm{~min}$ before the administration of the first stimulus. The flow rate in each channel was approximately $1 \mathrm{ml} / \mathrm{min}$ and was monitored during the course of each experiment. Minor variations in flow between channels were allowed for when secretory rates were calculated. Samples of perifusate were collected over 2 min periods, except when the concentration of glucose was increased above basal when they were obtained at 1 min intervals for $10 \mathrm{~min}$ after the change. The average time interval between the removal of the pancreas and the start of the experiment was $2 \mathrm{~h}$.

\section{Experimental Design}

Every experiment was carried out on four separate occasions, using pools of islets obtained from two collagenase digests each containing pancreatic tissue from three rats. On each occasion 
islets were assigned to one of three treatment groups. The control group was subjected to two stimulations with glucose $16.6 \mathrm{mmol} / 1$ applied between $40-60$ and $80-100 \mathrm{~min}$ of perifusion. The medium bathing the two experimental groups was modified as indicated in the text between 38 and $64 \mathrm{~min}$. All experimental islets were stimulated with glucose $16.6 \mathrm{mmol} / 1$ dissolved in normal medium between $80-100$ min.

On each occasion two to four channels were allocated to each treatment group and the mean rate of insulin secretion calculated for each group. The total insulin secreted by control islets during the initial stimulation period with glucose $16.6 \mathrm{mmol} / \mathrm{l}$ varied from day to day, with mean values ranging from 0.91 to $4.20 \mu \mathrm{g}$ insulin/ 20 min per islet. To account for this variation results were normalised [10]: the mean secretory rates of control and experimental islets measured on any particular occasion were expressed as percentages of the mean total secretion observed from control islets during the initial stimulation with glucose $16.6 \mathrm{mmol} / \mathrm{l}$ on that same occasion. Normalised results obtained on different occasions were combined and expressed as means \pm SEM. The statistical significance of results was assessed by two-tailed t-test for paired data, comparing the mean response of experimental islets prepared on any particular occasion with that of controls on the same occasion.

\section{Analytical Methods}

Insulin was assayed by radioimmunoassay [9] using purified rat insulin as standard (Novo Research Institute, Copenhagen, Denmark). The concentration of glucose in all media was measured using a glucose oxidase method.

\section{Results}

Shaded areas in Figures 1-4 illustrate that when control islets were exposed to two consecutive stimulations with glucose $16.6 \mathrm{mmol} / \mathrm{l}$ applied $20 \mathrm{~min}$ apart, insulin secretion in response to the second stimulus was always greater than that observed in response to the first. During the second period of stimulation the contribution of phase 1 to the total secretion also increased. (phase 1 as percentage of total: stimulus 1, $9.28 \pm 1.42$; stimulus $2,17.78 \pm 1.41 ; \mathrm{p}<0.01$; data from Fig. 1 A).

\section{Role of Glucose Metabolism}

The presence of mannoheptulose $(16 \mathrm{mmol} / \mathrm{l})$ during the initial stimulation period inhibited both the acute secretory response to glucose and its priming effect on the islet response to subsequent stimulation (Fig. 1A). Figure 1B demonstrates that glyceraldehyde $(16.6 \mathrm{mmol} / \mathrm{l})$ between $40-60 \mathrm{~min}$ of perifusion acutely stimulated insulin secretion, and enhanced the secretory response to a subsequent glucose load applied between 80-100 min of perifusion. The priming effect of glyceraldehyde was comparable to that observed in islets initially primed with glucose $16.6 \mathrm{mmol} / 1$ alone.

\section{Role of Calcium and the Microtubular System}

The omission of calcium from the perifusion medium during the initial stimulation period inhibited both the acute secretory response to glucose and its priming effect on the islet response to subsequent stimulation (Fig. $2 \mathrm{~A}) . \mathrm{D}_{2} \mathrm{O}(98 \% \mathrm{v} / \mathrm{v})$ inhibited insulin secretion during the initial stimulation period with glucose (Fig. 2B), and a rebound of secretion was observed when $\mathrm{D}_{2} \mathrm{O}$ was removed from the medium. The priming effect of glucose was also reduced by this treatment, since the maximum phase 1 secretion rate observed from $\mathrm{D}_{2} \mathrm{O}$-treated islets was significantly lower than control values during the second period of stimulation (maximum normalised secretory rates: phase 1 control, $11.65 \pm 1.39 ; \mathrm{D}_{2} \mathrm{O}$ treated, $7.30 \pm 1.37 ; p<0.01)$. However, since the maximum phase 1 secretory rate was still significantly $(p<0.05)$ greater than that observed from islets not previously stimulated with glucose but exposed to $\mathrm{D}_{2} \mathrm{O}$ alone (4.06 \pm 0.64 , normalised data), the priming effect of glucose was not completely abolished by $\mathrm{D}_{2} \mathrm{O}$.

\section{Effect of Theophylline}

The presence of theophylline $(5 \mathrm{mmol} / \mathrm{l})$ during the initial stimulation period greatly enhanced the acute secretory response to glucose, but did not influence its priming effect on the islet response to subsequent stimulation (Fig. 3). The inclusion of theophylline in medium containing basal glucose between 38-64 min of perifusion did not increase insulin secretion acutely or appear to have any effect on insulin release induced by glucose between $80-100 \mathrm{~min}$. During the latter period the contribution of the phase 1 response to the total secretion of theophylline-treated islets $(11.07 \pm 2.76 \%)$ was not significantly different from that observed in controls during the initial period of stimulation with glucose alone $(9.13 \pm 3.0 \%)$.

\section{Effect of Adrenaline}

Insulin secretion was inhibited when adrenaline $(10 \mu \mathrm{mol} / 1)$ was included in the perifusion medium during the initial stimulation period with glucose (Fig. 4). The priming effect of glucose was also reduced by this treatment since maximal rates of phase 1 secretion by adrenaline-treated islets during the second stimulation period were significantly lower than control values (maximum normalised secretory rates: phase 1 control, $11.37 \pm 0.9$; adrenaline-treated $4.85 \pm 1.11 ; \mathrm{p}<0.05$ ). However, the maximum phase 1 secretory rate was still significantly higher $(p<0.02)$ than that observed from 

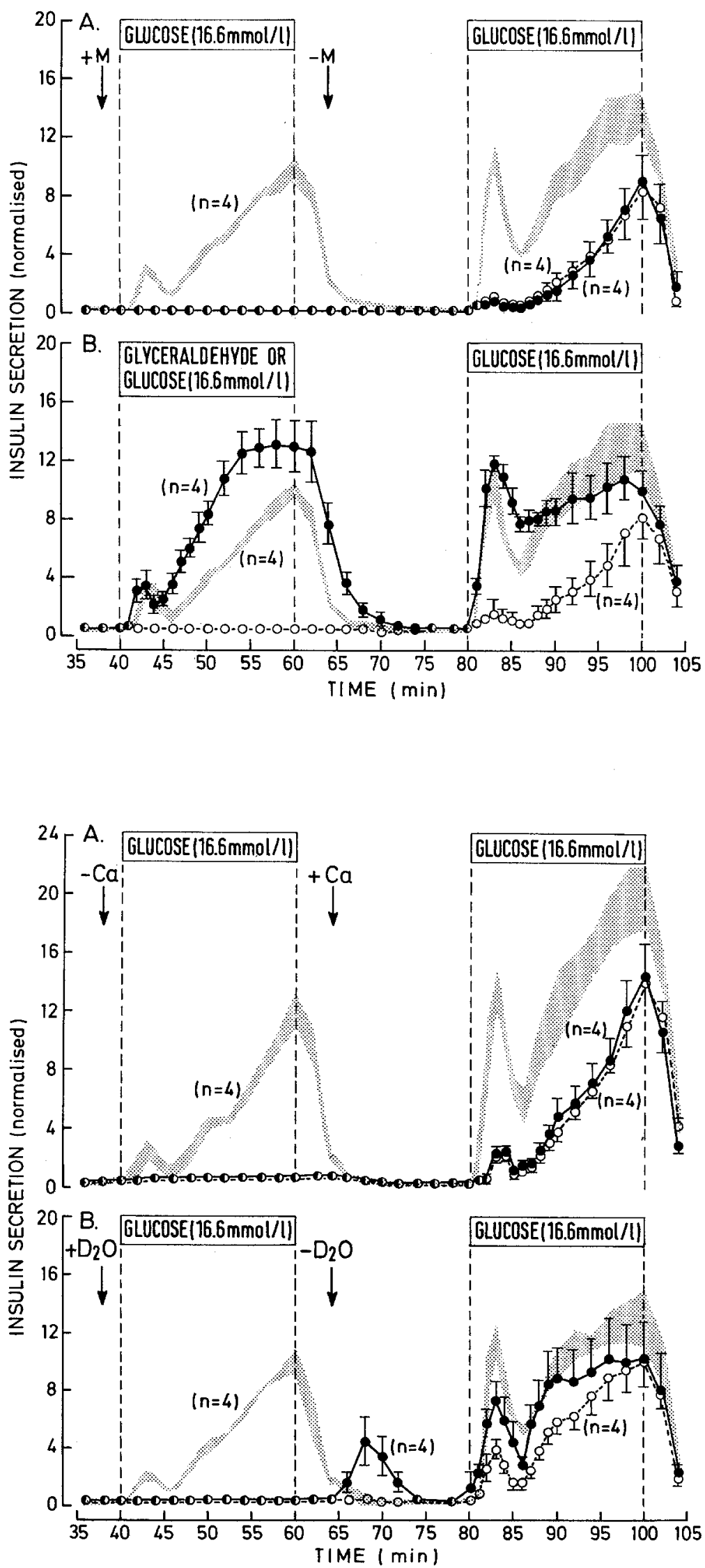

Fig. 1. Upper panel: Inhibitory effect of mannoheptulose $16.6 \mathrm{mmol} / 1(\mathrm{M})$ on the priming action of glucose on insulin secretion from isolated islets of Langerhans. Between $40-60$ min of perifusion control islets were stimulated with high glucose alone (shaded area) while experimental islets were exposed to either high glucose + mannoheptulose $(\bullet)$ or mannoheptulose dissolved in medium containing basal glucose $(0)$. Mannoheptulose was present in experimental media during the period indicated by arrows. All islets were exposed to high glucose alone between $80-100 \mathrm{~min}$. Lower panel: Enhancement of glucose-induced insulin secretion from isolated islets of Langerhans following stimulation with glyceraldehyde $16.6 \mathrm{mmol} / \mathrm{l}$. Between $40-60 \mathrm{~min}$ of perifusion control islets were stimulated with high glucose alone (shaded area) while experimental islets were exposed to glyceraldehyde in the presence of basal glucose $(\bullet)$ or basal glucose alone (O). All islets were exposed to high glucose alone between 80-100 min. All results represent means \pm SEM for normalised data
Fig. 2. Upper panel: Inhibitory effect of calcium deprivation on the priming action of glucose on insulin secretion from isolated islets of Langerhans. Between 40-60 min of perifusion control islets were stimulated with high glucose in normal medium (shaded area) while experimental islets were exposed to either high glucose dissolved in calcium-free medium ( $\bullet$ ) or calcium-free medium alone containing basal glucose ( 0 ). Calcium was excluded from experimental media during the period indicated by arrows. All islets were exposed to high glucose alone between $80-100 \mathrm{~min}$. Lower panel: Effect of deuterium oxide $\left(D_{2} O\right)(98 \% ; v / v)$ on the priming action of glucose on insulin secretion from isolated islets of Langerhans. Between 40-60 min of perifusion control islets were stimulated with high glucose alone (shaded area) while experimental islets were exposed to either high glucose dissolved in medium containing $\mathrm{D}_{2} \mathrm{O}(\bullet)$ or to medium containing $\mathrm{D}_{2} \mathrm{O}(\mathrm{O})$ and basal glucose. $\mathrm{D}_{2} \mathrm{O}$ was present in experimental islets during the period indicated by the arrows. All islets were exposed to high glucose alone between $80-100 \mathrm{~min}$. All results represent means \pm SEM for normalised data 

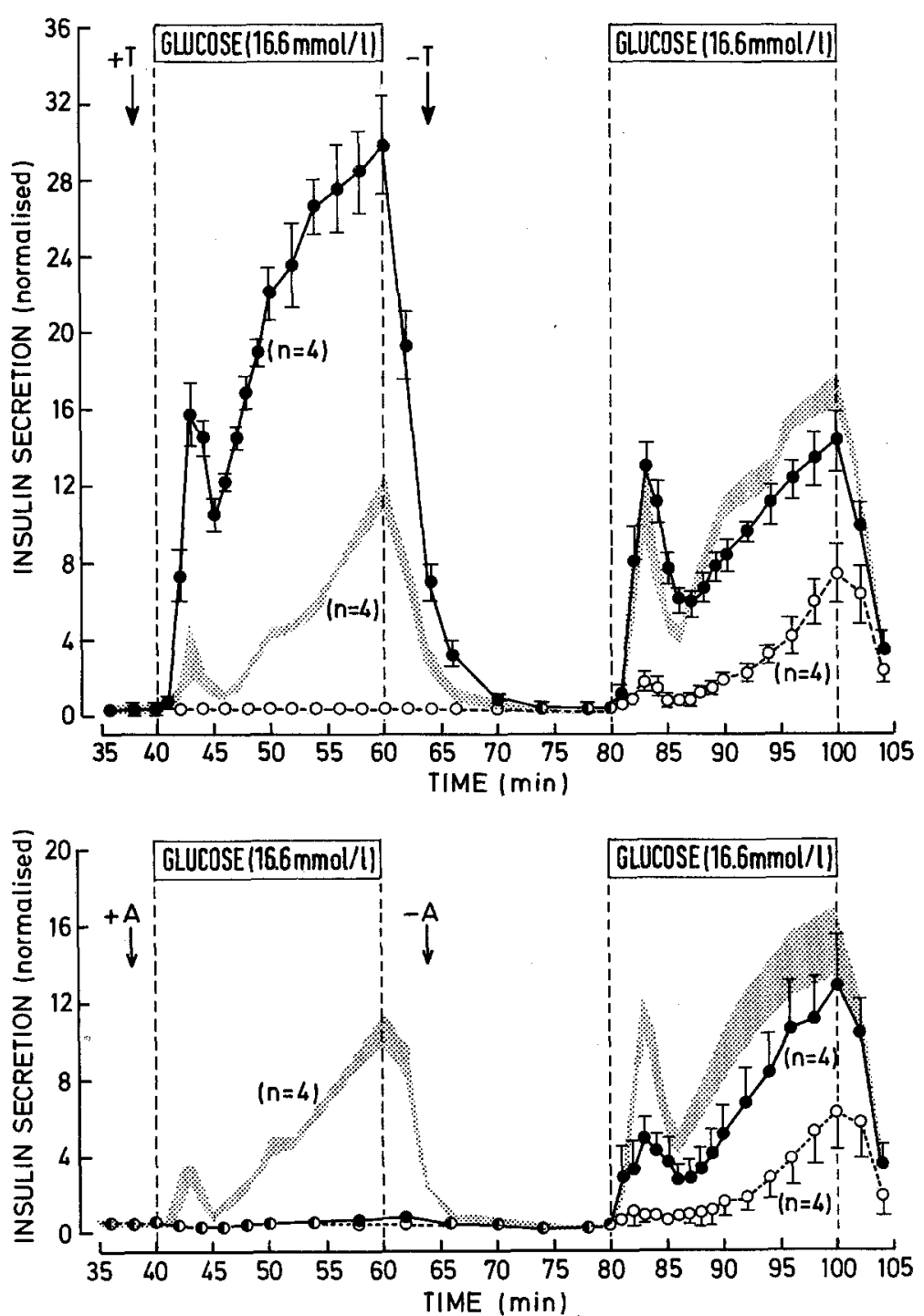

Fig. 3. Effect of theophylline $5 \mathrm{mmol} / 1$ on the priming action of glucose on insulin secretion from isolated islets of Langerhans. Between 40-60 min of perifusion control islets were stimulated with high glucose alone (shaded area) while experimental islets were exposed to high glucose + theophylline $(\bullet)$ or theophylline dissolved in medium containing basal glucose (0). Theophylline was present in experimental media during the period indicated by arrows. All islets were exposed to high glucose alone between $80-100 \mathrm{~min}$. Results represent means \pm SEM for normalised data

Fig. 4. Effect of adrenaline $10 \mu \mathrm{mol} / 1$ on the priming action of glucose on insulin secretion from isolated islets of Langerhans. Between $40-60 \mathrm{~min}$ of perifusion control islets were stimulated with high glucose along (shaded area) while experimental islets were exposed to high glucose + adrenaline $(\bullet)$ or adrenaline dissolved in medium containing basal glucose (0). Adrenaline was present in experimental media during the period indicated by arrows. All islets were exposed to high glucose alone between $80-100 \mathrm{~min}$. Results represent means \pm SEM for normalised data islets which had not been previously stimulated with glucose but exposed to adrenaline alone (1.12 \pm 0.81 , normalised data). The priming effect of glucose was therefore not completely abolished by adrenaline.

\section{Discussion}

The results confirm that a short period of stimulation with glucose primes the $\mathrm{B}$ cell, making it more responsive to subsequent stimulation with glucose [5-7]. The priming effect of glucose could be reproduced by the glycolytic intermediate glyceraldehyde, and prevented by mannoheptulose which inhibits the key glucose phosphorylating enzyme, high-Km hexokinase [12]. This confirms the findings of others [13] and suggests that glucose metabolism is involved in the priming process.
In contrast to the findings of an earlier investigation [13] these observations suggest that extracellular calcium is essential for the priming effect of glucose on the $\mathrm{B}$ cell. This discrepancy may relate to differing degrees of calcium depletion in the B cell since the acute secretory response to glucose, although greatly diminished, was not completely abolished (Fig. 2A) when calcium was removed from the medium perfusing the rat pancreas preparation used in earlier studies [13].

Since the metabolism of glucose is inhibited only slightly in a calcium-free medium [14], the present results suggest that calcium dependent processes, such as the activation of the microtubular microfilamentous system [15], may also be involved in glucose priming. This possibility is strengthened by the observation that $\mathrm{D}_{2} \mathrm{O}$, an agent which reversibly stabilises the microtubular system [11], reduced the 
priming effect of glucose (Fig. 2B). It is unlikely that this was due to an effect on islet glucose metabolism since $\mathrm{D}_{2} \mathrm{O}$ does not appear to influence either islet calcium uptake or insulin biosynthesis, both of which are reduced following inhibition of glucose metabolism [11]. However, it is important to note that the effect of $\mathrm{D}_{2} \mathrm{O}$ may not be entirely specific since this agent may interfere with the mobilisation of calcium from intracellular organelles in islets [16] and reduce total pancreatic oxygen consumption [17].

Experiments with theophylline, which elevates islet cyclic AMP levels by inhibiting cyclic nucleotide phosphodiesterase [18], did not produce any evidence that the generation of cyclic AMP can induce a primed state in the B cell. Others [13] have shown that the enhanced secretion of insulin which occurs after glucose priming is not accompanied by a simultaneous increase in islet cyclic AMP formation.

In contrast with studies in man [19] the present results show that adrenaline may impair the priming effect of glucose in vitro (Fig. 4). Although the mechanism is uncertain it is tempting to speculate that this may be related to the inhibitory effect of adrenaline on calcium uptake in islets [20].

Finally, the results of experiments with theophylline and adrenaline suggest that the magnitude of the acute insulin response to glucose is not related to the magnitude of the priming effect of glucose on insulin secretion. For example, theophylline markedly enhanced acute insulin secretion in response to glucose but did not affect the priming response. Conversely, adrenaline completely inhibited the acute insulin response to glucose, but only partially reduced the priming effect of glucose on insulin secretion.

Acknowledgements. We are grateful to Professor J. A. Strong and Dr. J.D. Baird for encouragement and helpful criticism during these studies, to Carol-Anne McKechnie, Nicola Christie and Susan Taylor for expert technical assistance, to the Animal Unit of the Western General Hospital for providing the animals used for this study, and to Mr. C.M. Ferrington for assistance with computerised handling of data.

\section{References}

1. Cerasi E, Luft R (1967) The plasma insulin response to glucose infusion in healthy subjects and in diabetes mellitus. Acta Endocrinol (Copenh) 55: 278-304

2. Porte D, Pupo AA (1969) Insulin responses to glucose: Evidence for a two pool system in man. J Clin Invest 48: 2309-2319

3. Grodsky GM, Bennett LL, Smith D, Nemechek K (1967) The effect of tolbutamide and glucose on the timed release of insulin from the isolated perfused pancreas. In: Butterfield WJH, Westering W (eds) Tolbutamide after ten years. Excerpta Medica Foundation, Amsterdam, p 11-21
4. Curry DL, Bennett LL, Grodsky GM (1968) Dynamics of insulin secretion by the perfused rat pancreas. Endocrinology 83: $572-584$

5. Cerasi E (1975) Potentiation of insulin release by glucose in man. I. Quantitative analysis of enhancement of glucoseinduced insulin secretion by pretreatment with glucose in normal subjects. Acta Endocrinol (Copenh) 79: 483-501

6. Grodsky GM (1972) A threshold distribution hypothesis for packet storage of insulin and its mathematical modelling. $J$ Clin Invest 51: 2047-2059

7. Ashby JP, Shirling D (1980) Evidence for priming and inhibitory effects of glucose on insulin secretion from isolated islets of Langerhans. Diabetologia 18: 417-421

8. Lacy PE, Kostianovsky M (1967) Method for isolation of intact islets of Langerhans from the rat pancreas. Diabetes 16: 35-39

9. Ashby JP, Speake RN (1975) Insulin and glucagon secretion from isolated islets of Langerhans: Effects of calcium ionophores. Biochem J 150: 89-96

10. Somers G, Van Obberghen E, Devis G, Ravazzola M, Malaisse-Lagae F, Malaisse WJ (1974) Dynamics of insulin release and the microtubular-microfilamentous system. III. Effect of colchicine upon glucose-induced insulin secretion. Eur J Clin Invest 4: 299-305

11. Malaisse WJ, Malaisse-Lagae F, Walker MO, Lacy PE (1971) The stimulus-secretion coupling of glucose-induced insulin release. V. The participation of a microtubular-microfilamentous system. Diabetes 20: 257-265

12. Zawalich WS (1979) Intermediary metabolism and insulin secretion from isolated rat islets of Langerhans. Diabetes 28 : 252-260

13. Grill V, Adamson U, Cerasi E (1978) Immediate and timedependent effects of glucose on insulin release from rat pancreatic tissue. Evidence for different mechanisms of action. J Clin Invest 61: 1034-1043

14. Hellman B, Idahl LA, Lernmark A, Sehlin JO, Taljedal IB (1974) The pancreatic B cell recognition of insulin secretagogues. Effects of calcium and sodium on glucose metabolism and insulin release. Biochem J 138: 33-45

15. Malaisse WJ (1973) Insulin secretion: multifactorial regulation for a single process of release. Diabetologia 9: 167-173

16. Malaisse WJ (1973) Theophylline induced translocation of calcium in the pancreatic beta cell: Inhibition by deuterium oxide. Nature 242: 189-190

17. Van Obberghen E, Somers G, Devis G, Ravazzola M, Malaisse-Lagae F, Orci L, Malaisse WJ (1974) Dynamics of insulin release and microtubular microfilamentous system. VI. Effect of $\mathrm{D}_{2} \mathrm{O}$. Endocrinology 95: 1518-1528

18. Montague W. Cook JR (1971) The role of adenosine $3^{\prime}: 5^{\prime}$ cyclic monophosphate in the regulation of insulin release by isolated islets of Langerhans. Biochem $\mathbf{J}$ 122: 115-120

19. Cerasi E (1975) Potentiation of insulin release by glucose in man. II. Role of the insulin response and enhancement of stimuli other than glucose. Acta Endocrinol (Copenh) 79: 502-510

20. Malaisse-Lagae F, Malaisse WJ (1971) Stimulus secretion coupling of glucose induced insulin release III. Uptake of ${ }^{45} \mathrm{Ca}$ by isolated islets of Langerhans. Endocrinology 88: 72-80

Received: August 28, 1980, and in revised form: February 5, 1981

Dr. J. P. Ashby

Department of Medicine

Wèstern General Hospital

Edinburgh EH5 2XU, UK 